\title{
Serine administration as a novel prophylactic approach to reduce the severity of acute pancreatitis during diabetes in mice
}

\author{
Rong Chen ${ }^{1} \cdot$ Thorsten Hornemann $^{2,3}$ (D) Saša Štefanić ${ }^{4}$ (D) Elisabeth M. Schraner ${ }^{5}$ (D) Richard Zuellig $^{6}$.

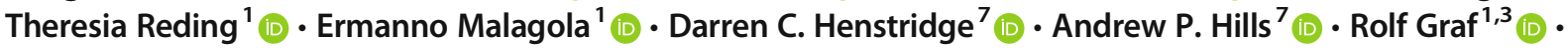 \\ Sabrina Sonda ${ }^{1,3,7}$ (D)
}

Received: 12 December 2019 / Accepted: 13 March 2020 / Published online: 8 May 2020

(C) Springer-Verlag GmbH Germany, part of Springer Nature 2020

\begin{abstract}
Aims/hypothesis Compared with the general population, individuals with diabetes have a higher risk of developing severe acute pancreatitis, a highly debilitating and potentially lethal inflammation of the exocrine pancreas. In this study, we investigated whether 1-deoxysphingolipids, atypical lipids that increase in the circulation following the development of diabetes, exacerbate the severity of pancreatitis in a diabetic setting.

Methods We analysed whether administration of an L-serine-enriched diet to mouse models of diabetes, an established method for decreasing the synthesis of 1-deoxysphingolipids in vivo, reduced the severity of acute pancreatitis. Furthermore, we elucidated the molecular mechanisms underlying the lipotoxicity exerted by 1-deoxysphingolipids towards rodent pancreatic acinar cells in vitro.

Results We demonstrated that L-serine supplementation reduced the damage of acinar tissue resulting from the induction of pancreatitis in diabetic mice (average histological damage score: 1.5 in L-serine-treated mice vs 2.7 in the control group). At the cellular level, we showed that L-serine decreased the production of reactive oxygen species, endoplasmic reticulum stress and cellular apoptosis in acinar tissue. Importantly, these parameters, together with DNA damage, were triggered in acinar cells upon treatment with 1-deoxysphingolipids in vitro, suggesting that these lipids are cytotoxic towards pancreatic acinar cells in a cellautonomous manner. In search of the initiating events of the observed cytotoxicity, we discovered that 1-deoxysphingolipids induced early mitochondrial dysfunction in acinar cells, characterised by ultrastructural alterations, impaired oxygen consumption rate and reduced ATP synthesis.

Conclusions/interpretation Our results suggest that 1-deoxysphingolipids directly damage the functionality of pancreatic acinar cells and highlight that an L-serine-enriched diet may be used as a promising prophylactic intervention to reduce the severity of pancreatitis in the context of diabetes.
\end{abstract}

Keywords 1 -Deoxysphingolipids $\cdot$ Diabetes $\cdot$ L-serine $\cdot$ Mitochondria $\cdot$ Pancreatitis

Electronic supplementary material The online version of this article (https://doi.org/10.1007/s00125-020-05156-x) contains peer-reviewed but unedited supplementary material, which is available to authorised users.

Sabrina Sonda

sabrina.sonda@utas.edu.au

1 Swiss Hepato-Pancreato-Biliary Center, Department of Visceral and Transplantation Surgery, University Hospital Zurich,

Zurich, Switzerland

2 Institute for Clinical Chemistry, University Hospital Zurich, Zurich, Switzerland

3 Zurich Center for Integrative Human Physiology (ZIHP), University of Zurich, Zurich, Switzerland
4 Institute of Parasitology, University of Zurich, Zurich, Switzerland

5 Institute of Veterinary Anatomy and Virology, University of Zurich, Zurich, Switzerland

6 Division of Endocrinology, Diabetes \& Clinical Nutrition, University Hospital Zurich, Zurich, Switzerland

7 School of Health Sciences, College of Health and Medicine, University of Tasmania, Launceston, TAS 7250, Australia 


\section{Research in context}

\section{What is already known about this subject?}

- Diabetes comorbidities have a severe impact on the management of the disease and the quality of life of patients

- Diabetes is a risk factor for acute pancreatitis and exacerbates the severity of the disease, for which no cure is currently available

- Atypical lipids known as 1-deoxysphingolipids are increased in the blood of individuals with diabetes

\section{What is the key question?}

- Do diabetes-derived 1-deoxysphingolipids damage pancreatic acinar cells in rodents and sensitise them to inflammatory insult?

\section{What are the new findings?}

- 1-Deoxysphingolipids are cytotoxic for pancreatic acinar cells

- The cascade of molecular events triggered by 1-deoxysphingolipids include mitochondrial dysfunction, oxidative stress and apoptosis of acinar cells

- Administration of L-serine, known to reduce 1-deoxysphingolipid synthesis in vivo, reduced the tissue damage associated with pancreatitis in mouse models of diabetes

\section{How might this impact on clinical practice in the foreseeable future?}

- Administration of L-serine may represent a promising prophylactic approach to limit the severity of pancreatitis in the context of diabetes

\begin{tabular}{|c|c|}
\hline \multicolumn{2}{|c|}{ Abbreviations } \\
\hline ATF4 & Activating transcription factor 4 \\
\hline Cer & Cerulein \\
\hline $\mathrm{CHOP}$ & $\begin{array}{l}\text { CCAAT-enhancer-binding protein }(\mathrm{C} / \mathrm{EBP}) \\
\text { homologous protein }\end{array}$ \\
\hline $\mathrm{C}_{18} \mathrm{SA}$ & $\mathrm{C}_{18}$ sphinganine \\
\hline $\mathrm{C}_{18} \mathrm{SO}$ & $\mathrm{C}_{18}$ sphingosine \\
\hline doxSA & 1-Deoxysphinganine \\
\hline doxSO & 1-deoxysphingosine \\
\hline ER & Endoplasmic reticulum \\
\hline$\gamma-\mathrm{H} 2 \mathrm{AX}$ & $\mathrm{H} 2 \mathrm{~A}$ histone family member $\mathrm{X}$ \\
\hline HSAN1 & $\begin{array}{l}\text { Hereditary sensory and autonomic neuropathy } \\
\text { type } 1\end{array}$ \\
\hline MINPEPA & $\begin{array}{l}\text { Recommendations for Minimum Information } \\
\text { for Publication of Experimental Pathology Data }\end{array}$ \\
\hline MTT & $\begin{array}{l}\text { 3-(4,5-Dimethylthiazol-2-yl)-2,5-diphenyltetra- } \\
\text { zolium bromide }\end{array}$ \\
\hline ROS & Reactive oxygen species \\
\hline $\mathrm{SRC}$ & Spare respiration capacity \\
\hline $\mathrm{TZZ}$ & Streptozotocin \\
\hline
\end{tabular}

\section{Introduction}

The development of comorbidities in individuals with diabetes represents a major burden as this complicates the management of the disease and reduces life expectancy [1]. Large epidemiological studies have shown that diabetes increases the risk of acute pancreatitis [2-4], an inflammatory disease characterised by excruciating pain and elevated morbidity rate. In addition, diabetes exacerbates the severity of the disease [5] and reduces the regenerative ability of the pancreas [6]. As severe pancreatitis is associated with high levels of mortality in humans and no effective cure is currently available, it is essential to identify novel approaches to mitigate the extent of the disease.

This study had two goals: (1) to elucidate molecular factors that contribute to aggravating pancreatitis in the context of pre-existing diabetes; and (2) to test whether interfering with the identified contributing factors reduces the severity of pancreatitis. We hypothesised that circulating molecules produced during diabetes may sensitise the pancreas to subsequent inflammatory injury. In this context, 1deoxysphingolipids are likely candidates to increase pancreatic sensitivity to damage. 1-Deoxysphingolipids are formed when alanine is used instead of serine in the first step of sphingolipid synthesis. This aberrant amino acid incorporation occurs either upon mutation of the synthetic enzyme serine-palmitoyl transferase, leading to alanine being preferentially utilised as a substrate, as is the case for individuals with hereditary sensory and autonomic neuropathy type I (HSAN1), or when amino acid metabolism is altered and the ratio of alanine:serine levels increase, as is the case for individuals with the metabolic syndrome and diabetes (reviewed previously [7]). 1-Deoxysphingolipids, recently identified as 
early biomarkers of diabetes [8-11], tend to accumulate in tissues as their intracellular catabolism is slower than standard sphingolipids [12]. In addition, they show cytotoxic properties towards different cell types (reviewed previously [7]). Despite their potential toxicity, 1-deoxysphingolipid synthesis can be readily inhibited in vivo by supplementation with the amino acid L-serine because the availability of serine determines the amount of 1-deoxysphingolipids formed. Accordingly, Lserine-enriched diets are currently being explored as a valid therapeutic approach for 1-deoxysphingolipid-dependent diseases (reviewed in [7, 13]).

In this study, we tested the hypothesis that 1deoxysphingolipids contribute to the severity of pancreatitis in the context of diabetes. Specifically, we utilised in vivo and in vitro approaches to investigate whether an L-serineenriched diet mitigates the development of pancreatitis in mouse models of diabetes and whether 1-deoxysphingolipids are directly cytotoxic for pancreatic acinar cells.

\section{Methods}

Reagents $\mathrm{C}_{18}$ sphinganine $\left(\mathrm{C}_{18} \mathrm{SA}\right)$ and $\mathrm{C}_{18} 1$ deoxysphinganine (doxSA; Avanti Polar Lipids, Alabaster, AL, USA) stock solutions were prepared as previously described [14], as BSA complexes, and added to cells at the concentrations indicated in the figure legends. BSA was used as control. Further reagent details are given in the electronic supplementary material [ESM] Methods.

Mammalian cell culture Primary acinar cells were isolated from pancreases of C57BL/6 mice (Envigo, Itingen, Switzerland) as previously described [15]. Primary myofibroblasts were isolated from pancreases of C57BL/6 mice using the outgrowth method [16]. Rat AR42J acinar cells (ATCC, Manassas, VA, USA) and rat ARIP ductal cells (ATCC), which routinely tested negative for mycoplasma contamination, were maintained as previously described [17]. Cell viability was determined by trypan blue exclusion, by the automated cell counter NucleoCounter NC-200 (Chemometec, Lillerød, Denmark) or by 3-(4,5-dimethylthiazol-2-yl)-2,5-diphenyltetrazolium bromide (MTT) assay (Sigma-Aldrich, Buchs, Switzerland), according to the manufacturer's instructions. Zymogen secretion in AR42J cells was stimulated by incubation with $50 \mathrm{mmol} / \mathrm{l}$ dexamethasone for $24 \mathrm{~h}$, following which sphinganine or doxSA were added for an additional $24 \mathrm{~h}$ incubation and an MTT assay was conducted.

Animal experiments All studies involving animals are reported in accordance with the Animal Research: Reporting of In Vivo Experiments (ARRIVE) and the Recommendations for Minimum Information for Publication of Experimental
Pathology Data (MINPEPA) guidelines. The mice used in this study were 8-week-old adult C57BL/6 male inbred mice (Envigo), with a body weight $\geq 25 \mathrm{~g}$. Cages containing litters were randomly assigned to the different experimental groups. The experimenters were aware of the group assignment during data collection in live animals (e.g. weight determination and blood glucose analysis). However, experimenters were blind to group assignment after samples were harvested and only at the end of data collection were results assigned to the different experimental groups. All data were included in the analyses.

Diabetes was induced via daily i.p. injection of $50 \mathrm{mg} / \mathrm{kg}$ streptozotocin (STZ), administered on 5 consecutive days. Diabetes establishment was determined by fasting blood glucose measured using a glucose meter (Acuu-Check; Roche, Basel, Switzerland). Acute pancreatitis was induced via six daily i.p. injections of $50 \mu \mathrm{g} / \mathrm{kg}$ cerulein (Cer), administered hourly on 2 consecutive days. Control animals received $0.9 \% \mathrm{NaCl}$ injections. For L-serine supplementation, mice were provided with a chow diet containing $10 \%$ L-serine (A04; SAFE, Augy, France). Standard chow diet was used as a control. No adverse effects were reported during the time frame of the experiments. Further details are animal experiments are provided in the ESM Methods.

Pathology data information Experimental pathology data were collected in accordance with the MINPEPA guidelines and experiments were designed to standardise animal handling, tissue harvesting and tissue processing. As per standard operating procedures, animals were anesthetised by isoflurane inhalation and received a midline laparotomy under continuing inhalation anaesthesia. Subsequently, a small piece of the pancreas, near the spleen, was dissected and snap frozen for subsequent RNA extraction. Blood was sampled by exsanguination via heart puncture, and the remaining organs were harvested for histology.

Immunohistochemistry and H\&E staining AR42J cells and tissues were fixed as described in the ESM Methods. For tissue samples, consecutive $3 \mu \mathrm{m}$-thick sections were prepared for H\&E staining and immunohistochemistry. Immunohistochemistry was used to analyse the following proteins in cells and tissues: cleaved caspase-3, activating transcription factor 4 (ATF4), phospho-histone H2A histone family member X ( $\gamma$-H2AX), Ki67, DNA damage inducible transcript 3 (DDIT3; also known as CCAAT-enhancerbinding protein $[\mathrm{C} / \mathrm{EBP}]$ homologous protein $[\mathrm{CHOP}])$, 4hydroxymonenal, perilipin-2 (also known as adipose differentiation-related protein $[\mathrm{ADFP}])$. The number of positive cells was normalised to the area exclusively occupied by pancreatic acinar tissue in each power field; The areas occupied by pancreatic ducts, islets and vessels were excluded from the analysis. Immunohistochemistry was also used to visualise mitochondria in live cells using MitoTracker Red 
CMXRos dye (Thermo Fisher Scientific, Waltham, MA, USA). Further details of procedures and antibodies are given in the ESM Methods.

Electron microscopy Electron microscopy analyses of AR42J cells were performed as described in the ESM Methods. Briefly, AR42J cells were treated with the lipids for $7 \mathrm{~h}$ and fixed. After washing, the samples were post-fixed, dehydrated in a graded series of ethanol and transferred to acetone for embedding in Epon. Ultrathin sections were stained with uranyl acetate and lead citrate and examined at an acceleration voltage of $100 \mathrm{kV}$ in a Philips CM 12 transmission electron microscope (Eindhoven, the Netherlands) equipped with a charge-coupled device (CCD) camera (Ultrascan 1000, Gatan, Pleasanton, CA, USA).

Seahorse assay AR42J cells $\left(1 \times 10^{4}\right)$ were treated for $7 \mathrm{~h}$ with $3 \mu \mathrm{mol} / 1$ sphinganine or doxSA in eight-well plates. Oxygen consumption rate was quantified with the Seahorse XFp Mito Stress Test Kit (103010-100; Bucher Biotec, Basel, Switzerland), according to the manufacturer's instructions.

\section{$\mathrm{Ca}^{2+}$, ATP and reactive oxygen species quantification} Quantification of $\mathrm{Ca}^{2+}$, ATP and reactive oxygen species (ROS) in AR42J cells incubated with $3 \mu \mathrm{mol} / \mathrm{l}$ sphinganine or doxSA was performed as described in the ESM Methods. In brief: for $\mathrm{Ca}^{2+}$ quantification, a fluorescent $\mathrm{Ca}^{2+}$ indicator (Fura-2, acetoxymethyl [AM]; F1201; Thermo Fisher Scientific) was used and fluorescence measured by flow cytometry; for ATP quantification, the CellTiter-Glo Luminescent Cell Viability assay (G7570, Promega, Madison, WI, USA) was used; and for ROS quantification, cells were incubated with $2^{\prime}, 7^{\prime}$-dichlorofluorescin diacetate (D6883, Sigma) and fluorescence was measured. For ROS inhibition, AR42J cells were treated with $1 \mathrm{mmol} / \mathrm{l}$ of the antioxidant Trolox (238,813; Sigma).

Sphingolipid analysis The composition of sphingoid bases was analysed in plasma and cell extracts by mass spectrometry, according to previous publications [11], as described in the ESM Methods. The sphingoid bases analysed included $\mathrm{C}_{16}$ sphingosine $\left(\mathrm{C}_{16} \mathrm{SO}\right), \mathrm{C}_{16}$ sphinganine $\left(\mathrm{C}_{16} \mathrm{SA}\right), \mathrm{C}_{17}$ sphingosine $\left(\mathrm{C}_{17} \mathrm{SO}\right), \mathrm{C}_{17}$ sphinganine $\left(\mathrm{C}_{17} \mathrm{SA}\right), \mathrm{C}_{18}$ sphingosine $\left(\mathrm{C}_{18} \mathrm{SO}\right), \mathrm{C}_{18} \mathrm{SA}, \mathrm{C}_{19}$ sphinganine $\left(\mathrm{C}_{19} \mathrm{SA}\right), \mathrm{C}_{20}$ sphingosine $\left(\mathrm{C}_{20} \mathrm{SO}\right), \mathrm{C}_{20}$ sphinganine $\left(\mathrm{C}_{20} \mathrm{SA}\right), \mathrm{C}_{18}$ phytosphingosine $\left(\mathrm{C}_{18}\right.$ PhytoSO), $\mathrm{C}_{18}$ sphingadiene $\left(\mathrm{C}_{18}\right.$ SAdiene $)$, doxSA and 1-deoxysphingosine (doxSO). Lipids were normalised using $\mathrm{C}_{18} \mathrm{SO}$ as an internal standard, the level of which remained stable under the different experimental conditions.

Transcript analysis Total RNA was extracted from pancreatic tissue using a method that included an 'on column' DNA digestion, as previously reported [18]. Transcript analyses was performed by real-time PCR, as described in the ESM Methods.

Biochemical analysis Levels of enzymatic activity of amylase and lipase were quantified in serum collected via heart puncture. Enzyme activities were measured using the Fuji DriChem 4000i analyser (FUJIFILM Corporation, Tokyo, Japan).

Statistical analysis Groups of $\geq 5$ animals were tested for each experimental group. The data are expressed as means \pm SEM. The statistical significance of differences in the means of experimental groups was determined using an unpaired twotailed Student's $t$ test or one-way analysis of variance followed by Dunnett's post-test (GraphPad Prism version 7; GraphPad Software; www.graphpad.com) and a probability value $<0.05$ was considered statistically significant.

Study approval All animal experiments were performed in accordance with Swiss federal animal regulations and approved by The Cantonal Veterinary Office Zurich.

\section{Results}

Comorbidity of diabetes and acute pancreatitis increases oxidative stress and apoptosis in acinar tissue Four weeks of diabetes (treatment regimen scheme depicted in Fig. 1a) did not damage acinar tissue, as shown by normal pancreatic histology (Fig. 1b) and lack of pathological levels of pancreatic enzymes released in blood (ESM Fig. 1a), the most common diagnostic marker of acinar tissue damage. Diabetes did not change the initial response to Cer, as levels of pancreatic enzymes in the blood were comparable in Certreated and -untreated mice $8 \mathrm{~h}$ after induction of the disease (ESM Fig. 1b). However, diabetes exacerbated the severity of acute pancreatitis, as seen by increased acinar tissue damage, cell infiltration and oedema (Fig. 1b). At a cellular level, diabetes-pancreatitis comorbidity increased oxidative damage (Fig. 1c), endoplasmic reticulum (ER) stress (Fig. 1d) and apoptosis (Fig. 1e) in acinar tissue.

Pancreatitis-induced oxidative damage may harm other organs, including the liver [19]. However, liver dysfunction was not evident in our experimental model, as liver enzymes in blood (ESM Fig. 2a), liver histology (ESM Fig. 2b) and steatosis (ESM Fig. 2c) were comparable amongst treatment groups.

Glucose levels increased in the blood of the two diabetic groups, but they did not rise further with diabetes-pancreatitis comorbidity (ESM Fig. 3a). Similarly, the comorbidity model was not associated with increased triacylglycerol levels (ESM Fig. 3b). 
Fig. 1 Diabetes increases ROS levels, ER stress and acinar apoptosis upon induction of pancreatitis. (a) Schematic representation of study protocol for diabetes induction with STZ and pancreatitis induction with Cer administration. Day 1 is the day of the first STZ injection. (b) $H \& E$ staining of pancreases and quantification of pancreatic tissue damage 3 days after the induction of pancreatitis. Asterisks indicate areas with prominent tissue damage. (c) Staining and quantification of lipid peroxidation with 4-

hydroxynoneal as a marker of oxidative stress, 3 days after the induction of pancreatitis. (d) Staining and quantification of CHOP levels 3 days after the induction of pancreatitis. (e) Staining and quantification of the apoptotic marker cleaved caspase-3, 3 days after induction of pancreatitis. Images are representative magnifications from the power field used to quantify stained cells; scale bars, $50 \mu \mathrm{m}$. Ctrl, control. Data are presented as mean $\pm \operatorname{SEM}(n \geq 5)$. $* p<0.05$ a

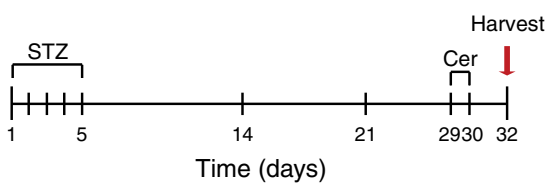

b
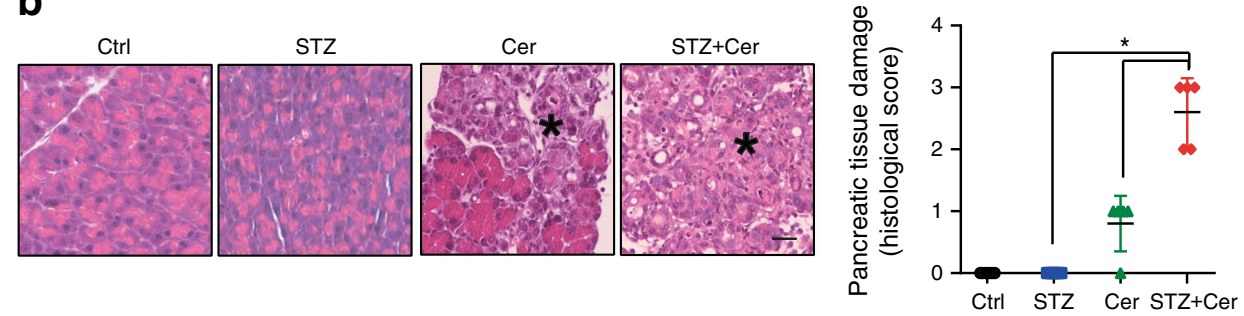

C
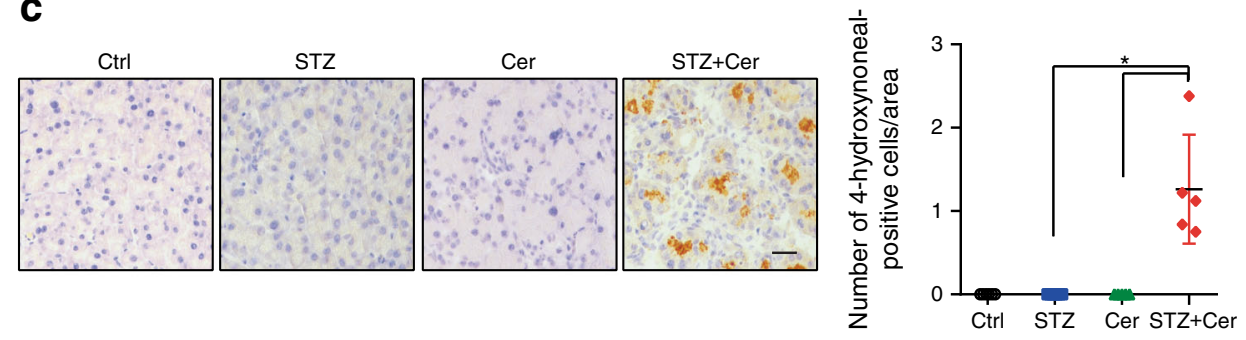

d
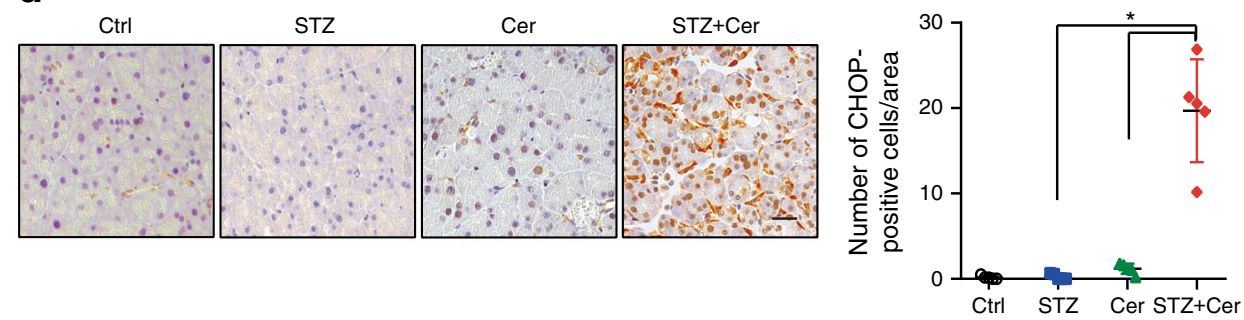

e

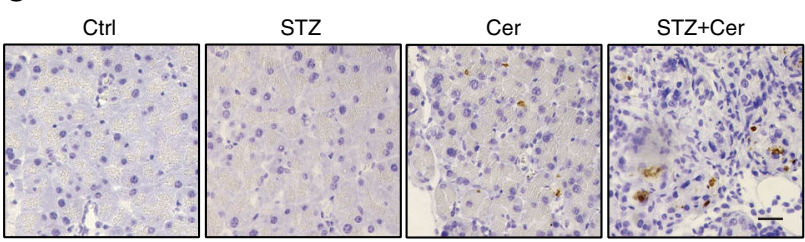

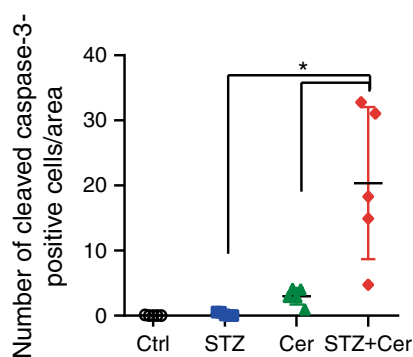

Finally, we quantified the amounts of standard sphingolipids and 1-deoxysphingolipids in blood by profiling the free sphingoid bases, sphinganine and sphingosine (obtained by acid hydrolysis of the $\mathrm{N}$-acyls and head groups), via liquid chromatography-mass spectrometry, as previously reported [20] (Fig. 2a-1). $\mathrm{C}_{18} \mathrm{SO}$ levels were used as an internal reference to normalise lipid content, as $\mathrm{C}_{18} \mathrm{SO}$ was the most abundant species detected (ESM Fig. 4a and previously reported [20]) and its levels remained stable after development of diabetes (ESM Fig. 4b; [20]) and pancreatitis (ESM Fig. 4b). 1-Deoxy sphingoid bases (doxSA and doxSO) levels were unchanged in mice with pancreatitis but increased in diabetic mice (Fig. 2a,b), confirming previous observations in rat models of diabetes [11, 20]. 1-Deoxysphingolipid levels did not further increase during diabetes-pancreatitis comorbidity, suggesting that 3 days of pancreatitis do not alter the production of these metabolites.

Oral L-serine supplementation ameliorates pancreatitis during diabetes comorbidity To test whether the increased acinar damage observed during diabetes-pancreatitis comorbidity derives from increased levels of circulating 1- 
Fig. 2 Plasma concentrations of diabetes and pancreatitis. (a-l) Mass spectrometry analyses of the levels of circulating (Ctrl) animals, upon induction of pancreatitis with Cer and diabetes with STZ, and in the comorbidity model (STZ + Cer). Data were normalised using $\mathrm{C}_{18} \mathrm{SO}$ as an internal control. $\mathrm{C}_{16} \mathrm{SA}, \mathrm{C}_{16}$ sphinganine; $\mathrm{C}_{16} \mathrm{SO}, \mathrm{C}_{16}$ sphingosine; $\mathrm{C}_{17} \mathrm{SA}, \mathrm{C}_{17}$ sphinganine; $\mathrm{C}_{17} \mathrm{SO}, \mathrm{C}_{17}$ sphingosine; $\mathrm{C}_{18}$ PhytoSO, $\mathrm{C}_{18}$ phytosphingosine; $\mathrm{C}_{18}$ SAdiene, $\mathrm{C}_{18}$ sphingadiene; $\mathrm{C}_{18} \mathrm{SO}, \mathrm{C}_{18}$ sphingosine; $\mathrm{C}_{19} \mathrm{SA}, \mathrm{C}_{19}$ sphinganine; $\mathrm{C}_{20} \mathrm{SA}, \mathrm{C}_{20}$ sphinganine; $\mathrm{C}_{20} \mathrm{SO}, \mathrm{C}_{20}$ sphingosine. Data are presented as mean $\pm \operatorname{SEM}(n \geq 4) . * p<0.05$ for group comparisons $(\mathbf{a}, \mathbf{b}$; with or without STZ) or individual comparisons $(\mathbf{d}, \mathbf{h}, \mathbf{i})$ sphingolipids upon induction of sphingolipid species in control
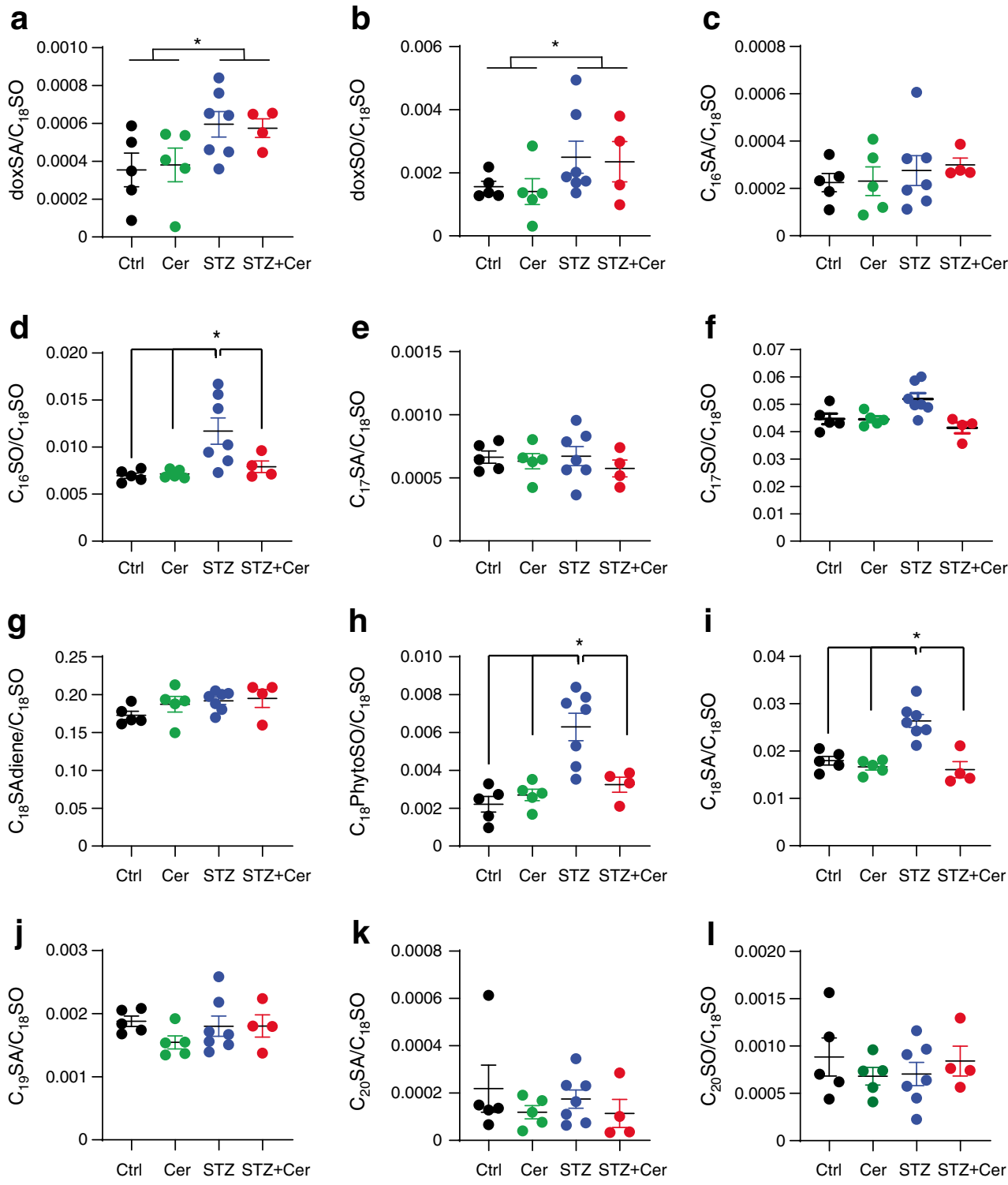

deoxysphingolipids, we reduced 1-deoxysphingolipid synthesis by oral L-serine supplementation (treatment regimen scheme depicted in Fig. 3a), an effective treatment to lower plasma concentrations of 1-deoxysphingolipids in humans and animal models, including during STZ-induced diabetes [20, 21]. Supplementation with an L-serine-enriched diet (the macronutrient and energy composition of which is presented in Table 1) did not change animal weight (ESM Fig. 5) but reduced the amount of circulating doxSA in STZ + Cer groups (Fig. 3b; all treatment groups are shown for comparison in ESM Fig. 6a) without lowering the levels of other sphingolipids (ESM Fig. $6 \mathrm{~b}, \mathrm{STZ}+\mathrm{Cer}$ groups). In the STZ group, the decrease in doxSA levels induced by L-serine was evident as a trend, but it did not reach statistical significance due to data variability.

Supplementation with L-serine in the comorbidity model improved tissue morphology and decreased injury markers, including tissue damage (average histological damage score:
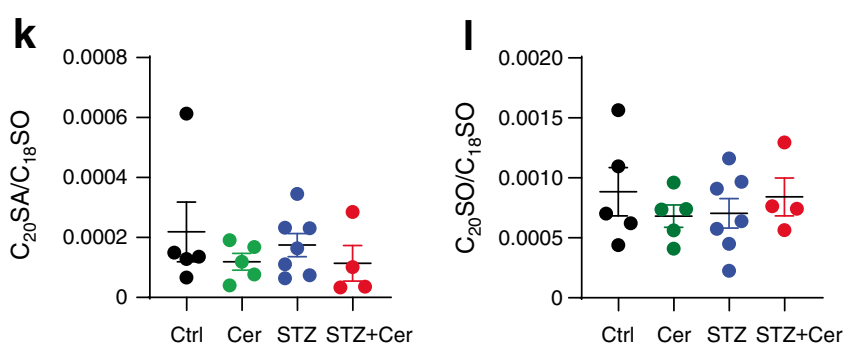

1.5 in L-serine-treated mice vs 2.7 in the control group), oxidative damage, ER stress and cell apoptosis (Fig. 3c-f; all treatment groups are shown for comparison in ESM Fig. 7a-d).

An L-serine-enriched diet did not protect acinar cells from the initial injury induced by Cer as diagnostic levels of pancreatic enzymes in serum did not decrease upon L-serine administration (ESM Fig. 8a). In addition, reduced pancreatic damage was not associated with improved blood glucose levels (ESM Fig. 8b) or insulin expression (ESM Fig. 8c), which were comparable in the diabetic groups.

Collectively, these results show that prophylactic oral administration of L-serine was beneficial during pancreatitisdiabetes comorbidity. Importantly, the beneficial effects of Lserine were not observed in mice subjected to pancreatitis alone, suggesting that L-serine does not act as a general prosurvival factor for acinar cells, but it rather operates via molecular events induced by diabetes. 
a

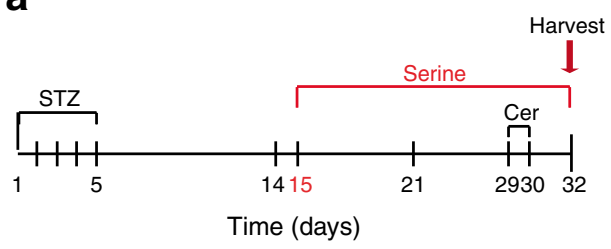

b

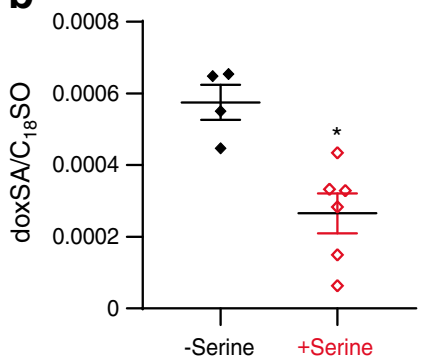

C
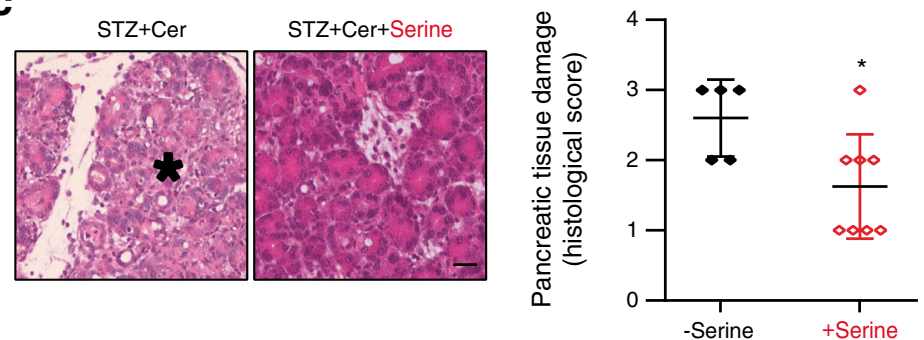

d
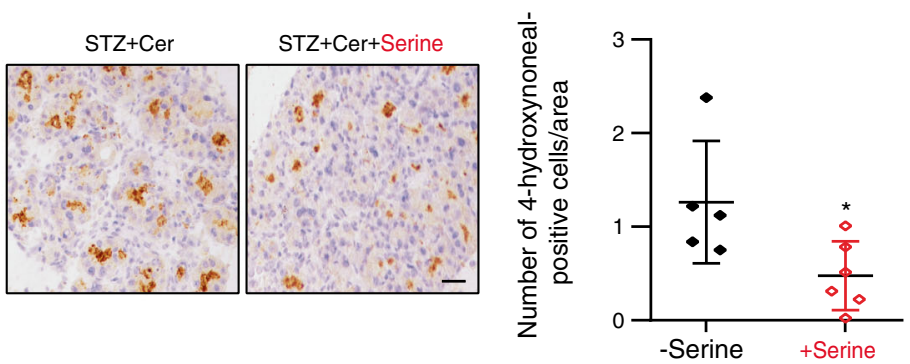

e
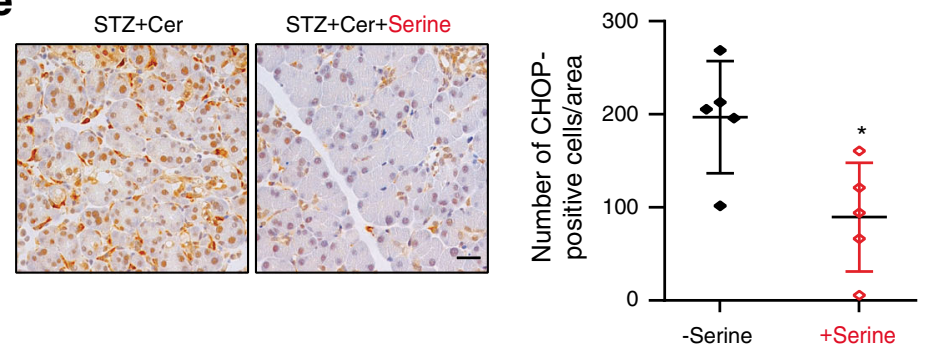

$\mathbf{f}$

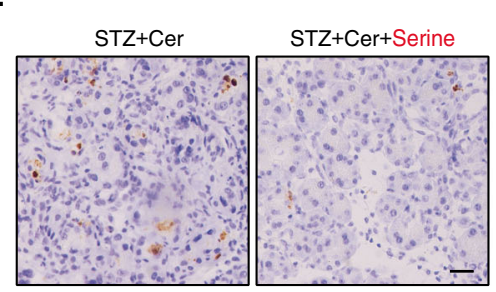

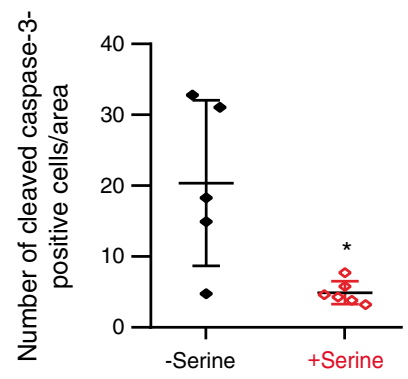

oxidative stress, 3 days after the induction of pancreatitis in diabetic mice in the presence or absence of L-serine supplementation. (e) Staining and quantification of the ER stress marker CHOP 3 days after the induction of pancreatitis in diabetic mice in the presence or absence of L-serine supplementation. (f) Staining and quantification of the apoptotic marker cleaved caspase-3, 3 days after the induction of pancreatitis in diabetic mice in the presence or absence of L-serine supplementation. Images are representative magnifications from the power field used to quantify stained cells; scale bars, $50 \mu \mathrm{m}$. Data are presented as mean $\pm \operatorname{SEM}(n \geq 4) . * p<0.05$ mice in the presence or absence of L-serine supplementation. The asterisk in the micrograph indicates area with prominent tissue damage. (d) Staining and quantification of lipid peroxidation with 4-hydroxynoneal as a marker of 
Table 1 Macronutrient and energy composition of mouse diets used in this study

\begin{tabular}{lcc}
\hline Composition & Standard chow diet & 10\% L-serine-enriched diet \\
\hline Protein (\%) & 15.5 & 21.8 \\
Fat (\%) & 3.0 & 2.7 \\
Minerals (\%) & 4.4 & 4.0 \\
Cellulose (\%) & 3.7 & 3.4 \\
Starch (\%) & 41.8 & 37.4 \\
Sugars (\%) & 3.1 & 2.8 \\
NFE (\%) & 58.0 & 53.8 \\
Energy (kJ/kg) & $13,723.52$ & $13,949.45$ \\
\hline
\end{tabular}

1-Deoxysphingolipids are cytotoxic for pancreatic acinar cells As we observed that an L-serine diet reduced both acinar damage and 1-deoxysphingolipids levels in vivo, we then tested whether 1-deoxysphingolipids were directly toxic to pancreatic acinar cells in vitro. Incubation of isolated primary acini with low micromolar concentrations of doxSA for $15 \mathrm{~h}$ significantly reduced the number of viable acinar cells (Fig. 4a). As observed for primary acini, $15 \mathrm{~h}$ incubation with doxSA reduced the viability of AR42J cells, the most commonly used pancreatic acinar cell line (Fig. 4b), and triggered apoptosis (Fig. 4c).
Fig. 4 doxSA is cytotoxic for pancreatic acinar cells. (a) Quantification of live cell number of primary acini following $15 \mathrm{~h}$ incubation with $3 \mu \mathrm{mol} / 1$ of sphinganine (SA) or doxSA and representative micrographs of treated cells. (b) Quantification of AR42J live cell number by trypan blue exclusion assay following $15 \mathrm{~h}$ incubation with $3 \mu \mathrm{mol} / \mathrm{l}$ of the lipids. (c) Staining of the apoptotic marker cleaved caspase-3 in AR42J cells after $15 \mathrm{~h}$ incubation with the lipids. Nuclei are stained with DAPI (blue); $n=3$. (d) Quantification of metabolic activity by MTT assay in AR42J acinar cells treated for $24 \mathrm{~h}$ with SA or doxSA at the indicated concentrations. (e) Quantification of AR42J live cell number by trypan blue exclusion assay following $24 \mathrm{~h}$ incubation with the lipids at the indicated concentrations. (f,g) Mass spectrometry quantification of doxSA (f) and doxSO (g) in AR42J cells following incubation with $3 \mu \mathrm{mol} / 1 \mathrm{SA}$ or doxSA for the indicated times. Lipid amount normalised by number of AR42J cells. (h) Quantification of metabolic activity by MTT assay in AR42J acinar cells treated for $24 \mathrm{~h}$ with SA or doxSA at the indicated concentrations in the presence of $100 \mathrm{nmol} / \mathrm{l} \mathrm{Cer}$. Ctrl, control. Scale bars, $100 \mu \mathrm{m}$. Data are presented as mean \pm SEM $(n \geq 3)$; $* p<0.05$ for individual comparisons, as indicated
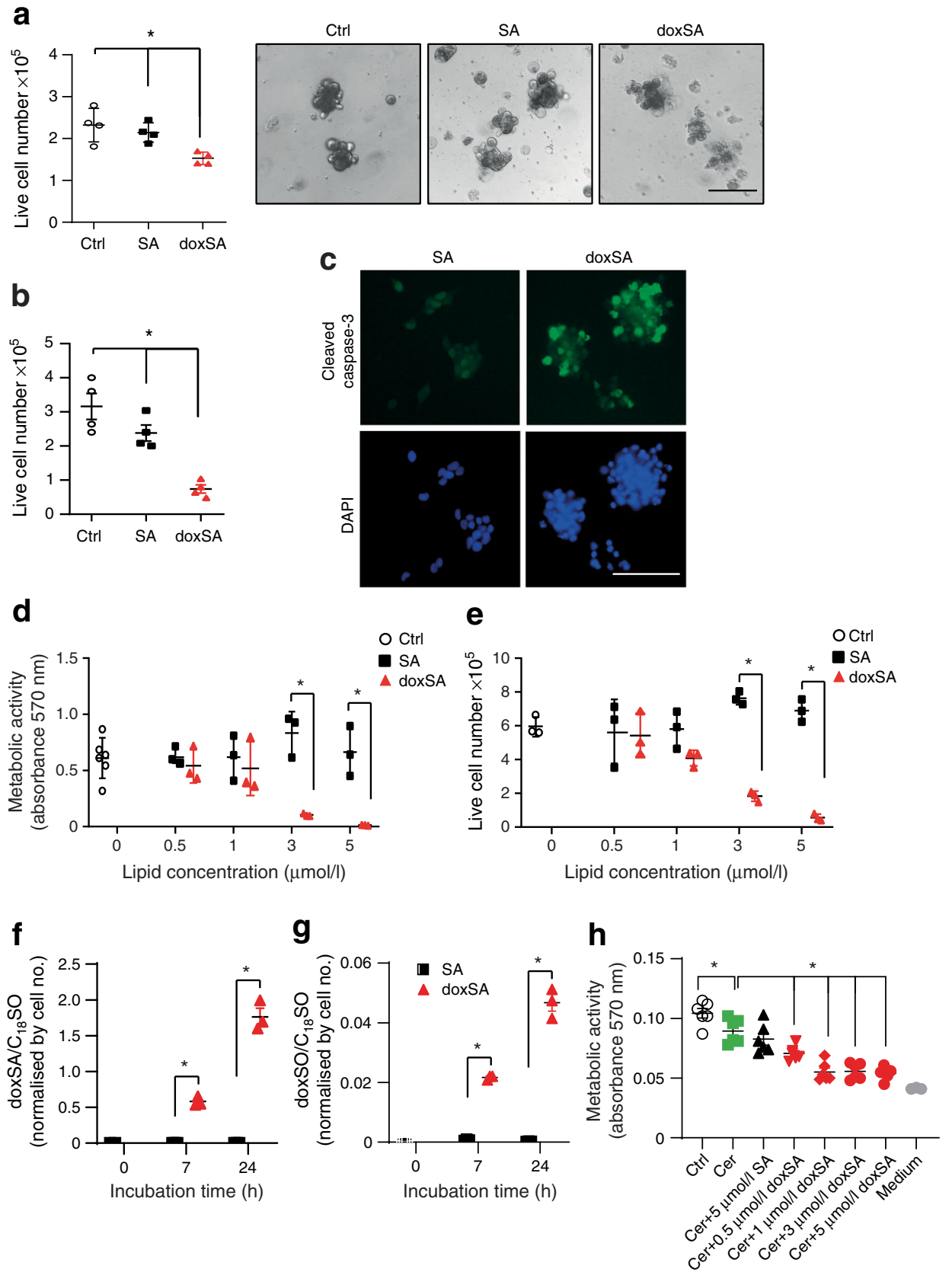

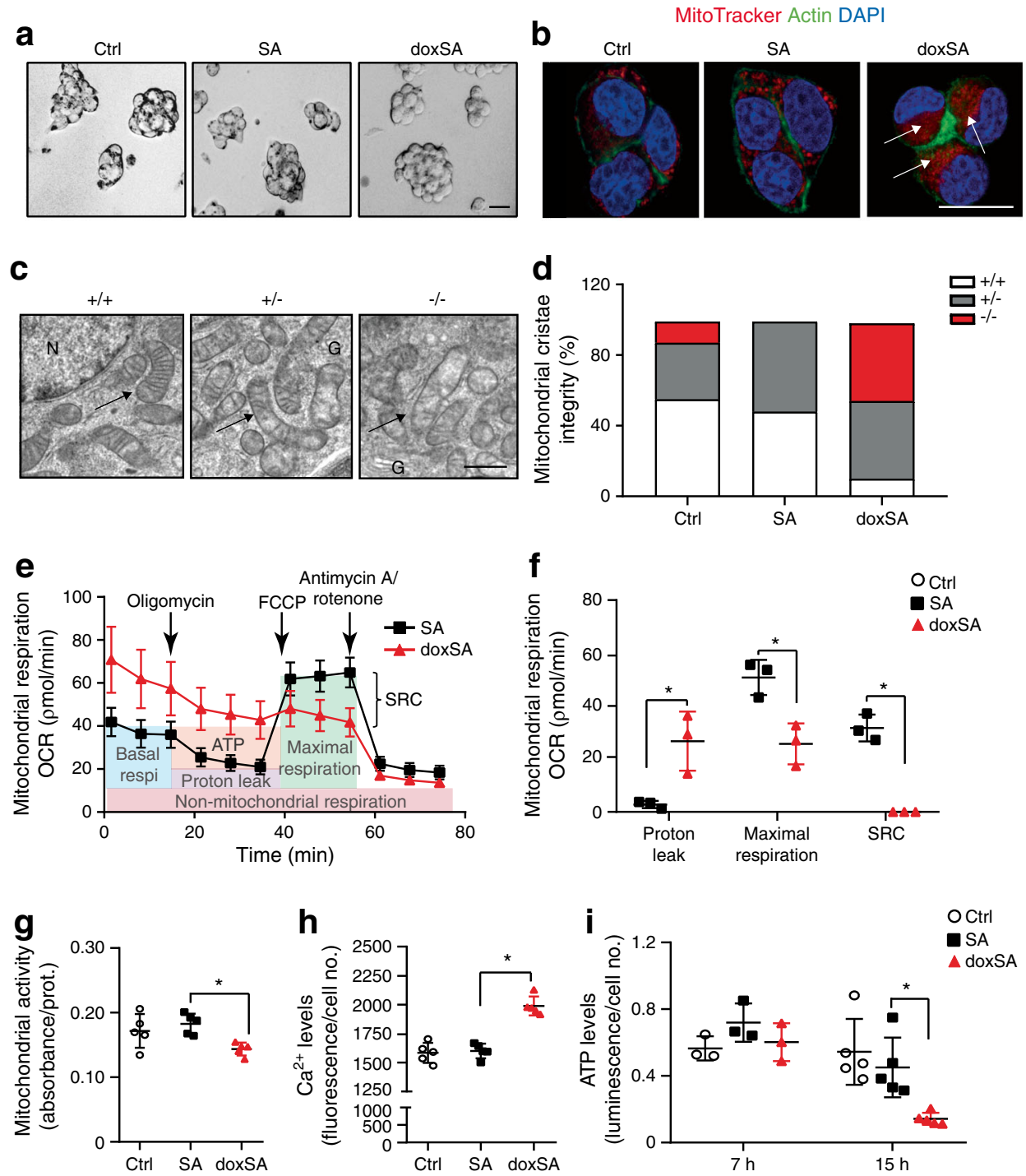

Fig. 5 doxSA induces mitochondrial dysfunction in pancreatic acinar cells. (a) Representative micrographs of AR42J cells treated with $3 \mu \mathrm{mol} / \mathrm{l}$ of sphinganine (SA) or doxSA for $7 \mathrm{~h}$ and stained with trypan blue. Note the absence of stained cells. Scale bar, $50 \mu \mathrm{m}$. (b) Single plane confocal images of AR42J cells upon $7 \mathrm{~h}$ treatment with $3 \mu \mathrm{mol} / 1$ of SA or doxSA. Mitochondria are stained with MitoTracker (red), actin is stained with phalloidin (green) and nuclei are stained with DAPI (blue). Note how mitochondria cluster together towards the apical pole of the cells in the presence of doxSA (arrows). Scale bar, $50 \mu \mathrm{m}$. (c) Electron micrographs showing mitochondrial cristae ultrastructure upon $7 \mathrm{~h}$ incubation with $3 \mu \mathrm{mol} / 1$ of SA or doxSA. Cristae integrity is defined as normal (+/+; well defined and regular), intermediate $(+/-$; irregular) or compromised $(-/-$; poorly defined or absent). Scale bar, $1 \mu \mathrm{m}$. (d) Quantification of cells with normal $(+/+)$, intermediate $(+/-)$ or compromised $(-/-)$ cristae

morphology following $7 \mathrm{~h}$ incubation with $3 \mu \mathrm{mol} / \mathrm{l}$ of each lipid. Data are expressed as per cent of cells detected in 20 images per group. (e) Quantification of mitochondrial respiration by Seahorse assay in AR42J cells treated for $7 \mathrm{~h}$ with $3 \mu \mathrm{mol} / 1$ doxSA or SA. (f) Quantification of proton leak, maximal respiration and SRC in cells treated for $7 \mathrm{~h}$ with $3 \mu \mathrm{mol} / 1$ of each lipid. (g) Quantification of MTT conversion normalised by protein content (prot.) in AR42J cells upon $7 \mathrm{~h}$ treatment with $3 \mu \mathrm{mol} / 1$ of the lipids. (h) Quantification of $\mathrm{Ca}^{2+}$ levels in AR42J cells upon $7 \mathrm{~h}$ treatment with $3 \mu \mathrm{mol} / 1$ of the lipids. (i) Quantification of ATP levels in AR42J cells upon $7 \mathrm{~h}$ treatment with $3 \mu \mathrm{mol} / \mathrm{l}$ of the lipids. FCCP, carbonyl cyanide-4-(trifluoromethoxy)phenylhydrazone; Basal respi, basal respiration; G, Golgi apparatus; N, nucleus; OCR, oxygen consumption rate. Data are presented as mean $\pm \operatorname{SEM}(n \geq 3) . * p<0.05$

Incubation with doxSA for $24 \mathrm{~h}$ compromised the viability of AR42J cells in a dose-dependent manner, as shown by reduced metabolic activity, as measured by MTT assay (Fig. $4 \mathrm{~d}$ ), and a reduced number of live cells, as measured by trypan blue exclusion (Fig. $4 \mathrm{e}$ ), with $3 \mu \mathrm{mol} / 1$ and $5 \mu \mathrm{mol} / 1$ doxSA vs sphinganine treatment at the same concentrations. Incubation

with doxSA also reduced metabolic activity when zymogen secretion in AR42J cells was stimulated with dexamethasone [22] (ESM Fig. 9a).

In addition, doxSA toxicity was time-dependent, as treatment with a $0.5 \mu \mathrm{mol} / 1$ concentration became cytotoxic when the incubation was prolonged for $72 \mathrm{~h}$, as compared with 
Fig. 6 doxSA increases ROS levels and ER stress in pancreatic acinar cells. (a) Quantification of ROS levels in AR42J cells incubated with $3 \mu \mathrm{mol} / 1$ sphinganine (SA) or doxSA for the indicated times. (b) Staining with the DNA damage marker $\gamma$ $\mathrm{H} 2 \mathrm{AX}$ after $15 \mathrm{~h}$ treatment with $3 \mu \mathrm{mol} / 1$ of the lipids; $n=3$. (c) qPCR analysis of expression of the stress marker Hsp 72 upon incubation with $3 \mu \mathrm{mol} / 1$ of the lipids for the indicated times. (d) Staining with the ER stress marker AFT4 after $15 \mathrm{~h}$ treatment with $3 \mu \mathrm{mol} / 1$ of each of the lipids; $n=3$. (e) qPCR analysis of Chop expression upon incubation with $3 \mu \mathrm{mol} / \mathrm{l}$ of the lipids. (f) Quantification of ROS formation after $15 \mathrm{~h}$ of $3 \mu \mathrm{mol} / 1 \mathrm{lipid}$ treatment in the absence and presence of the antioxidant Trolox. (g) qPCR analysis of Chop expression after $15 \mathrm{~h}$ of $3 \mu \mathrm{mol} / 1$ lipid treatment in the absence and presence of Trolox. mRNA expression levels in (c), (e) and (g) are normalised to $18 \mathrm{~S}$ RNA expression and expressed as relative to expression in control animals. Data are shown as fold vs 0 h. (h) Quantification of live cell number after $15 \mathrm{~h}$ of $3 \mu \mathrm{mol} / 1$ lipid treatment in the absence and presence of Trolox; data are expressed as per cent of control (Ctrl) cells. Scale bars, $100 \mu \mathrm{m}$. Data are presented as mean \pm $\operatorname{SEM}(n \geq 3) . * p<0.05$
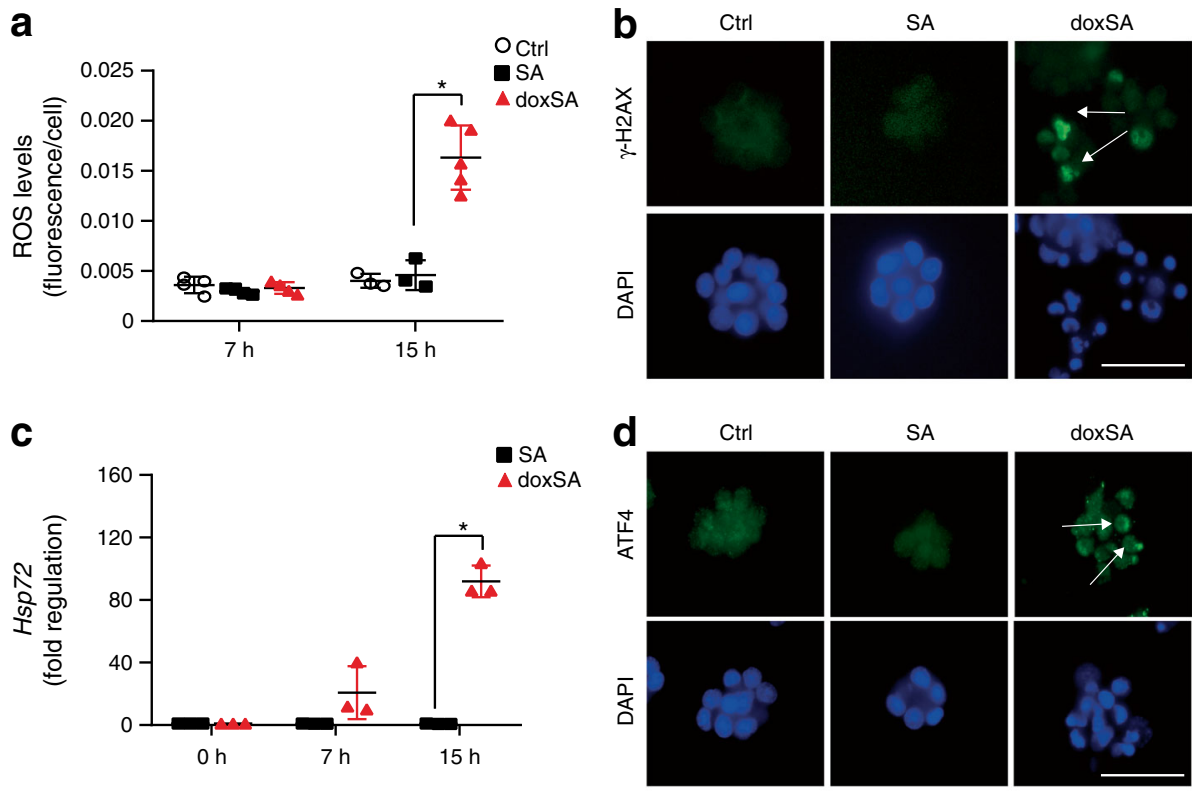

doxSA

e
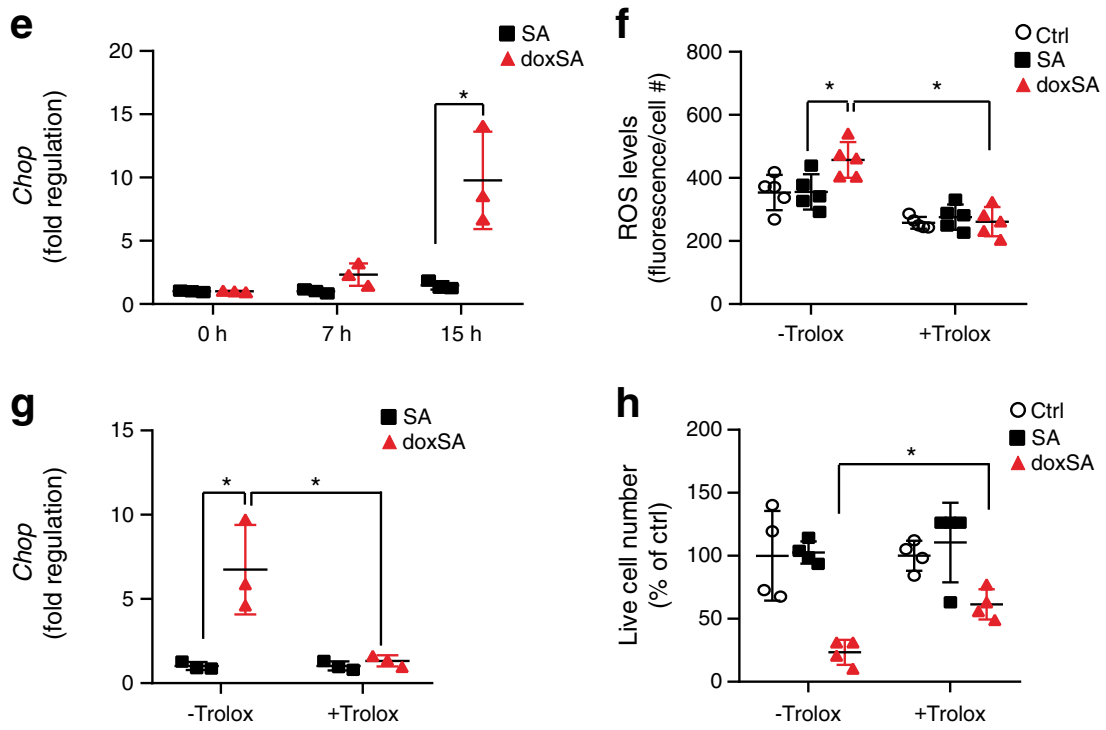

sphinganine treatment (ESM Fig. 9b). doxSA reduced the metabolic activity of ARIP ductal cells (ESM Fig. 9c) and primary pancreatic myofibroblasts (ESM Fig. 9d), suggesting that dysfunctions of other types of pancreatic cells may aggravate pancreatitis in the comorbidity model.

Lipidomic profiling of AR42J cells showed that cellular levels of doxSA and its downstream metabolite doxSO increased in a time-dependent manner upon doxSA incubation (Fig. 4f,g), suggesting that 1-deoxysphingolipids accumulate in acinar cells. The full sphingolipid profile is shown in ESM Fig. 10.

Finally, exposure of AR42J cells to doxSA, even at nontoxic $0.5 \mu \mathrm{mol} / \mathrm{l}$ concentrations, increased Cer-induced toxicity (Fig. 4h, ESM Fig. 11), suggesting that 1deoxysphingolipids sensitise acinar cells to additional insults.
doxSA compromises mitochondrial respiration and leads to mitochondrial dysfunction We then investigated whether doxSA drives acinar apoptosis by perturbing the functionality of mitochondria, since: (1) mitochondria play key roles in activating apoptosis in mammalian cells [23]; and (2) doxSA accumulates in mitochondria [24]. Treatment with $3 \mu \mathrm{mol} / 1$ doxSA for $7 \mathrm{~h}$, a time point when cell death was not yet observed (Fig. 5a), lead to accumulation of mitochondria in the apical region of acinar cells (Fig. 5b), and perturbed organelle ultrastructure and decreased the integrity of mitochondrial cristae (Fig. 5c,d), where cellular respiration occurs (full size electron micrographs of treated cells are shown in ESM Fig. 12). Analysis of the respiration process using the Seahorse technology demonstrated that the pattern of oxygen consumption rate was dramatically different in acinar cells incubated 
with doxSA (Fig. 5e), and it was characterised by increased proton leakage, reduced spare respiration capacity (SRC) and reduced maximal respiration (Fig. 5f) as compared with cells treated with sphinganine. SRC is regulated by the activity of mitochondrial succinate dehydrogenase, also known as mitochondrial complex II [25], the enzymatic activity of which is measured by MTT assay. doxSA decreased the cellular processing of MTT (Fig. 5g), suggesting that reduced succinate dehydrogenase activity contributes to the low SRC in doxSA-treated cells. Reduced succinate dehydrogenase activity is associated with increased levels of $\mathrm{Ca}^{2+}[26]$, an important signalling molecule that modulates mitochondrial function. Consistent with this, we found that intracellular $\mathrm{Ca}^{2+}$ concentration in AR42J cells increased $7 \mathrm{~h}$ after doxSA incubation, as compared with cells treated with sphinganine (Fig. $5 h)$.

Finally, ATP levels decreased after $15 \mathrm{~h}$ of doxSA treatment (Fig. 5i), suggesting that perturbation of the electron transport chain resulted in energy deficiency in acinar cells.

doxSA induces ROS production and ER stress Impaired mitochondrial function is associated with higher generation of ROS [27], where ROS can either result from or cause mitochondrial dysfunction. We found that ROS levels increased after $15 \mathrm{~h}$ of doxSA incubation, as compared with sphinganine treatment, but not after $7 \mathrm{~h}$ of treatment, when defective mitochondrial respiration was observed (Fig. 6a). These findings suggest that ROS production was a consequence rather than a cause of doxSAinduced mitochondrial dysfunction.

ROS triggers oxidative damage in the cells, which impairs the integrity of cellular components, including DNA molecules. Similarly, doxSA induced DNA damage in acinar cells, as demonstrated by increased phosphorylation of histone $\gamma$-H2AX, a marker for double-strand DNA breaks (Fig. 6b).

Excessive ROS production is often associated with stress of the ER [28]. Accordingly, we found that doxSA increased the expression of Hsp72 (also known as Hspala; Fig. 6c), an inducible member of the heat shock protein family, which is upregulated upon exposure to environmental stress [29]. One of the molecular pathways activated during ER stress involves sequential steps of protein kinase RNA-like endoplasmic reticulum kinase (PERK)-mediated eukaryotic translation initiation factor $2 \alpha$ (eIF $2 \alpha$ ) phosphorylation, upregulation of ATF4, and induction of CHOP (as reviewed previously [30]). We found that both ATF4 (Fig. 6d) and Chop (also known as Ddit3; Fig. 6e) were elevated in acinar cells upon doxSA incubation.

Finally, inhibition of ROS generation with the antioxidant Trolox (Fig. 6f) reduced the expression of Chop (Fig. 6g) and increased the number of live cells (Fig. 6h) in the presence of doxSA.
Collectively, our results show that increased ROS production following doxSA treatment drives oxidative damage in acinar cells, with consequent induction of ER stress, compromised DNA integrity and cell death.

\section{Discussion}

Acute pancreatitis is a major cause of hospitalisation for gastrointestinal disorders and its incidence is increasing around the world [31, 32]. The global epidemic of diabetes is likely to contribute to this increase, as diabetes is a risk factor for higher incidence and severity of pancreatitis. Thus, a better understanding of the underlying factors influencing pancreatitis in individuals with diabetes is essential for the development of novel therapeutic interventions.

In our study, we revealed three important elements associated with the pathophysiology of pancreatitis during diabetes. Namely, we found that 1-deoxysphingolipids, which are typically elevated in individuals with diabetes, are cytotoxic for pancreatic acinar cells in a cell-autonomous manner. In addition, we discovered that early mitochondrial dysfunction in acinar cells is a key molecular mechanism underlying 1deoxysphingolipid toxicity. Finally, we showed that oral supplementation of L-serine, a well-documented approach to lower the levels of circulating 1-deoxysphingolipids, effectively reduces the severity of pancreatitis induced during diabetes.

doxSA is cytotoxic for pancreatic acinar cells Increasing concentrations of doxSA progressively reduce acinar cell viability. The fact that doxSA triggered cell death and apoptosis at concentrations in the low micromolar range indicates that doxSA is 100 times more potent than fatty acids, which induce cellular stress and lipotoxicity in AR42J cells at 200 500 micromolar concentrations [33]. This finding supports the notion that even the comparatively low concentrations of circulating 1-deoxysphingolipids detected during diabetes [9] may be hazardous for acinar cells.

We also showed that doxSA progressively accumulates in acinar cells and exerts a time-dependent cytotoxicity, with non-toxic concentrations becoming toxic after prolonged exposure. This observation is consistent with the concept that, due to their structural characteristics, 1-deoxysphingolipids are degraded inside cells at a much slower rate than standard sphingolipids [12] and compromise cell functionality when they reach a certain threshold.

The robust cytotoxic effect of 1-deoxysphingolipids in acinar cells in vitro presented molecular characteristics like the ones observed in vivo during diabetes-pancreatitis comorbidity. However, despite this similarity, it is likely that additional mechanisms contribute to the phenotypes observed in vivo, where low concentrations of 1-deoxysphingolipids 
are present in the circulation for an extended amount of time. In this regard, the in vivo phenotypes may also derive from a concerted action of different molecular factors originating from the development of diabetes, including hyperglycaemia and decreased insulin availability, and the contribution of different cell types. In support of this hypothesis, insulin administration in a diabetic setting improved pancreatitis [6].

On the other hand, an indication that 1-deoxysphingolipids can be toxic to pancreatic acinar cells even independently from diabetes derives from experiments in transgenic mice, which harbour the C133W mutation in the Sptlc1 gene, encoding the sphingolipid synthetic enzyme serine palmitoyltransferase [34]. Sptlc1-C133W is the most common mutation in individuals suffering from HSAN1 [35] and results in increased synthesis of 1-deoxysphingolipids [14]. SPTLC $1^{\mathrm{C} 133 \mathrm{~W}}$ transgenic mice display increased 1deoxysphingolipid levels, peripheral neuropathy and, importantly, degeneration of pancreatic acinar cells, while pancreatic islets are well preserved [34], possibly linking 1deoxysphingolipid levels to acinar toxicity.

Molecular mechanisms of doxSA-induced cytotoxicity In addition to acinar cells, 1-deoxysphingolipids are cytotoxic towards other primary cells, including neurons, fibroblasts and pancreatic beta cells [7]. The molecular mechanisms leading to cell death reported to date may be specific for different cell types. In the case of pancreatic acinar cells, we identified a chain of cellular events that lead to increased ROS production and oxidative stress. Importantly, ROS production was shown to be a major trigger of cell death, as counteracting ROS by antioxidant treatment limited doxSA-induced toxicity. However, the fact that antioxidant treatment did not completely rescue cell death suggests that additional molecular effectors not yet identified may contribute to the observed toxicity.

How can exposure to 1-deoxysphingolipids lead to increased ROS in acinar cells? The available data pinpoints to the possible involvement of mitochondria as mediators of ROS production. First, the respiratory chain of mitochondria is responsible for the majority of ROS synthesised by cells (as reviewed previously $[36,37])$. Second, doxSA accumulates in mitochondria [24]. Third, we observed that doxSA induced a range of morphological and functional alterations in the mitochondria of acinar cells. Finally, we demonstrated that mitochondrial dysfunction preceded the cellular increase of ROS. Collectively, these data strongly suggest that ROS generation is a consequence of doxSA targeting and impairing mitochondria. Further analyses are required to elucidate the mechanisms by which doxSA triggers mitochondrial dysfunction and consequent cell death. One possibility is that doxSA, or its metabolites, intercalates with and physically damages mitochondrial membranes by forming protein-permeable pores through which proteins that initiate the execution phase of apoptosis are released. This scenario would mirror the cellular action of ceramide (reviewed in [38]), and it would be consistent with the fact that: (1) doxSA is readily converted into 1-deoxyceramide inside the cells; and (2) inhibition of ceramide synthesis prevents doxSA-induced cytotoxicity $[24,39,40]$. Additionally, doxSA could compromise the activity of selected mitochondrial proteins. Given the increase in $\mathrm{Ca}^{2+}$ levels observed in the presence of doxSA, it is tempting to speculate that the lipid alters the functionality of proteins involved in $\mathrm{Ca}^{2+}$ transport. In support of this possibility, ceramide was shown to modulate the function of $\mathrm{Ca}^{2+}$ transporters, including the $\mathrm{Na}^{2+} / \mathrm{Ca}^{2+}$ exchanger, ryanodine receptors and L-type $\mathrm{Ca}^{2+}$ channels [41-43]. The observed re-localisation of mitochondria may also be linked to perturbation of $\mathrm{Ca}^{2+}$ levels, as mitochondria act as an important regulator of $\mathrm{Ca}^{2+}$ levels in acinar cells by performing $\mathrm{Ca}^{2+}$ uptake and, thus, shaping the intracellular localisation of $\mathrm{Ca}^{2+}$ signalling [44]. In addition, mitochondria relocalisation was observed during aberrant $\mathrm{Ca}^{2+}$ uptake in acinar cells [45].

An important concept for a translational application of our results is that all the processes altered in acinar cells upon treatment with doxSA in vitro, namely mitochondrial dysfunction, aberrant $\mathrm{Ca}^{2+}$ homeostasis, ROS production and oxidative stress, play a prominent role in the development of acute pancreatitis (reviewed previously [46]). Interestingly, while the use of anti-oxidants to treat pancreatitis led to variable results in the clinic, pharmacological interventions aiming to prevent mitochondrial dysfunction showed a much more promising outcome [47], emphasising the importance of mitochondrial preservation for pancreatic homeostasis.

L-serine supplementation reduces the severity of pancreatitis during diabetes We discovered that L-serine supplementation reduced the level of circulating doxSA and ameliorated acinar tissue damage following pancreatitis in diabetic mice. Importantly, L-serine did not improve the outcome of pancreatitis in the absence of diabetes, supporting the notion that Lserine targets a factor present during diabetes. While we and others showed that doxSA increases in the blood following diabetes onset and that it accumulates in acinar cells when administered in vitro, an open question of this study is whether doxSA accumulates in the pancreas during diabetes and whether its tissue levels are reduced upon L-serine administration. Further studies are required to clarify this, as the low and highly variable lipid levels we detected in the tissue of animals precluded an accurate quantification (data not shown).

L-Serine supplementation did not change levels of doxSO, a downstream metabolite of doxSA. While additional analyses will clarify whether prolonged L-serine supplementation is required to reduce the level of this lipid, the data suggest that reduction of doxSO is not strictly required to ameliorate pancreatic tissue damage. These results are a foundation to further explore the use of L-serine supplementation as a novel 
prophylactic intervention for diabetes-pancreatitis comorbidity. Importantly, existing and ongoing clinical studies support the use of L-serine supplementation as a safe and effective intervention. Most of the studies completed to date have focused on the neuroprotective effects of L-serine in diseases characterised by elevated 1-deoxysphingolipid levels, such as HSAN1 [21, 48, 49] and diabetes [20]. In addition, the beneficial effects of L-serine treatment have been reported for other neurological and non-neurological diseases, such as the Guamanian amyotrophic lateral sclerosis (ALS)/ Parkinsonism/dementia complex [50, 51], Rett-like syndrome [52], genetic neurological diseases linked to L-serine deficiency [53], oxidative stress resulting from high-fat diet $[54,55]$ and colitis [56]. Finally, L-serine supplementation showed beneficial effects in a genetic model of type 1 diabetes, lowering the incidence of the disease, reducing the degree of insulitis and ameliorating blood glucose homeostasis [57]. Given the promising outcomes of L-serine administration in this diverse range of diseases, future studies are warranted to comprehensively investigate the molecular mechanisms triggered by this amino acid and, thus, elucidate disease pathophysiology. Besides reducing 1-deoxysphingolipids synthesis, additional cellular processes influenced by Lserine administration include $N$-methyl-D-aspartate (NMDA) receptor activation after isomerisation to Dserine $[52,58]$, expression of the ER chaperone protein disulphide isomerase [59] and mitochondrial function [60]. Whether 1-deoxysphingolipids are a common underlying factor in these processes is currently unknown.

Conclusions and future perspectives In this study, we discovered that doxSA is lipotoxic towards pancreatic cells and is likely to contribute to the pathophysiology of diabetespancreatitis comorbidity. In line with this hypothesis, we demonstrated that L-serine administration is an effective prophylactic approach to reduce both the levels of 1deoxysphingolipids and the severity of acute pancreatitis in diabetic mice. In this regard, further studies are warranted to evaluate the protective effects of L-serine also in the chronic stages of pancreatitis and in the development of multiple organ dysfunction. In addition, further investigations are necessary to explore the prophylactic effect of L-serine in high-fat-diet-induced diabetes, where elevation of 1deoxysphingolipid levels correlates with increased plasma triacylglycerols [61], which are a known risk factor for pancreatitis $[62,63]$.

Acknowledgements The authors thank S. Suriyanarayanan, U. Suess, I. Kleiber-Schaaf and A. Garcete-Bärtschi (University Hospital Zurich, Zurich, Switzerland) for their excellent technical assistance.
Data availability The data are available on request from the authors.

Funding This research received grants from the Swiss National Science Foundation (Grant no. 310030-146725) and the Amélie Waring Foundation.

Authors' relationships and activities The authors declare that there are no relationships or activities that might bias, or be perceived to bias, their work.

Contribution statement The authors of this manuscript contributed in the study design, acquisition, analysis and interpretation of data, and critical revision of the manuscript. RC performed experiments, generated and analysed data and wrote the manuscript; SSt, EMS, TR and EM performed experiments, generated and analysed data and revised the manuscript; TH, RZ, DCH, APH and RG analysed data and revised the manuscript; SSo designed the study and wrote the manuscript. All authors approved the submitted version. SSo is the guarantor of this work.

\section{References}

1. Gregg EW, Sattar N, Ali MK (2016) The changing face of diabetes complications. Lancet Diabetes Endocrinol 4(6):537-547. https:// doi.org/10.1016/S2213-8587(16)30010-9

2. Keech A, Simes RJ, Barter P et al (2005) Effects of long-term fenofibrate therapy on cardiovascular events in 9795 people with type 2 diabetes mellitus (the FIELD study): randomised controlled trial. Lancet 366(9500):1849-1861. https://doi.org/10.1016/S01406736(05)67667-2

3. Girman CJ, Kou TD, Cai B et al (2010) Patients with type 2 diabetes mellitus have higher risk for acute pancreatitis compared with those without diabetes. Diabetes Obes Metab 12(9):766-771. https://doi.org/10.1111/j.1463-1326.2010.01231.x

4. Noel RA, Braun DK, Patterson RE, Bloomgren GL (2009) Increased risk of acute pancreatitis and biliary disease observed in patients with type 2 diabetes: a retrospective cohort study. Diabetes Care 32(5):834-838. https://doi.org/10.2337/dc08-1755

5. Shen HN, Chang YH, Chen HF, Lu CL, Li CY (2012) Increased risk of severe acute pancreatitis in patients with diabetes. Diabet Med 29(11):1419-1424. https://doi.org/10.1111/j.1464-5491. 2012.03680.x

6. Zechner D, Spitzner M, Bobrowski A, Knapp N, Kuhla A, Vollmar B (2012) Diabetes aggravates acute pancreatitis and inhibits pancreas regeneration in mice. Diabetologia 55(5):1526-1534. https://doi. org/10.1007/s00125-012-2479-3

7. Lone MA, Santos T, Alecu I, Silva LC, Hornemann T (2019) 1Deoxysphingolipids. Biochim Biophys Acta Mol Cell Biol Lipids 1864(4):512-521. https://doi.org/10.1016/j.bbalip.2018.12.013

8. Mwinyi J, Bostrom A, Fehrer I et al (2017) Plasma 1deoxysphingolipids are early predictors of incident type 2 diabetes mellitus. PLoS One 12(5):e0175776. https://doi.org/10.1371/ journal.pone. 0175776

9. Othman A, Saely CH, Muendlein A et al (2015) Plasma 1deoxysphingolipids are predictive biomarkers for type 2 diabetes mellitus. BMJ Open Diabetes Res Care 3(1):e000073. https://doi. org/10.1136/bmjdrc-2014-000073

10. Wei N, Pan J, Pop-Busui R et al (2014) Altered sphingoid base profiles in type 1 compared to type 2 diabetes. Lipids Health Dis 13(1):161. https://doi.org/10.1186/1476-511X-13-161

11. Othman A, Rutti MF, Ernst D et al (2012) Plasma deoxysphingolipids: a novel class of biomarkers for the metabolic 
syndrome? Diabetologia 55(2):421-431. https://doi.org/10.1007/ s00125-011-2384-1

12. Alecu I, Othman A, Penno A et al (2017) Cytotoxic 1deoxysphingolipids are metabolized by a cytochrome P450-dependent pathway. J Lipid Res 58(1):60-71. https://doi.org/10.1194/jlr. M072421

13. Holm LJ, Buschard K (2019) L-serine: a neglected amino acid with a potential therapeutic role in diabetes. APMIS 127(10):655-659. https://doi.org/10.1111/apm.12987

14. Penno A, Reilly MM, Houlden $\mathrm{H}$ et al (2010) Hereditary sensory neuropathy type 1 is caused by the accumulation of two neurotoxic sphingolipids. J Biol Chem 285(15):11178-11187. https://doi.org/ 10.1074/jbc.M109.092973

15. Means AL, Meszoely IM, Suzuki K et al (2005) Pancreatic epithelial plasticity mediated by acinar cell transdifferentiation and generation of nestin-positive intermediates. Development 132(16):37673776. https://doi.org/10.1242/dev.01925

16. Bachem MG, Schneider E, Gross H et al (1998) Identification, culture, and characterization of pancreatic stellate cells in rats and humans. Gastroenterology 115(2):421-432. https://doi.org/10. 1016/s0016-5085(98)70209-4

17. Bombardo M, Malagola E, Chen R, Rudnicka A, Graf R, Sonda S (2018) Ibuprofen and diclofenac treatments reduce proliferation of pancreatic acinar cells upon inflammatory injury and mitogenic stimulation. Br J Pharmacol 175(2):335-347. https://doi.org/10. 1111/bph.13867

18. Graf R, Schiesser M, Lussi A, Went P, Scheele GA, Bimmler D (2002) Coordinate regulation of secretory stress proteins (PSP/reg, PAP I, PAP II, and PAP III) in the rat exocrine pancreas during experimental acute pancreatitis. J Surg Res 105(2):136-144. https://doi.org/10.1006/jsre.2002.6387

19. Batcioglu K, Gul M, Uyumlu AB, Esrefoglu M (2009) Liver lipid peroxidation and antioxidant capacity in cerulein-induced acute pancreatitis. Braz J Med Biol Res 42(9):776-782. https://doi.org/ 10.1590/s0100-879x2009000900001

20. Othman A, Bianchi R, Alecu I et al (2015) Lowering plasma 1deoxysphingolipids improves neuropathy in diabetic rats. Diabetes 64(3):1035-1045. https://doi.org/10.2337/db14-1325

21. Garofalo K, Penno A, Schmidt BP et al (2011) Oral L-serine supplementation reduces production of neurotoxic deoxysphingolipids in mice and humans with hereditary sensory autonomic neuropathy type 1. J Clin Invest 121(12):4735-4745. https://doi.org/10.1172/JCI57549

22. Logsdon CD, Moessner J, Williams JA, Goldfine ID (1985) Glucocorticoids increase amylase mRNA levels, secretory organelles, and secretion in pancreatic acinar AR42J cells. J Cell Biol 100(4):1200-1208. https://doi.org/10.1083/jcb.100.4.1200

23. Wang C, Youle RJ (2009) The role of mitochondria in apoptosis. Annu Rev Genet 43(1):95-118. https://doi.org/10.1146/annurevgenet-102108-134850

24. Alecu I, Tedeschi A, Behler N et al (2017) Localization of 1deoxysphingolipids to mitochondria induces mitochondrial dysfunction. J Lipid Res 58(1):42-59. https://doi.org/10.1194/jlr. M068676

25. Pfleger J, He M, Abdellatif M (2015) Mitochondrial complex II is a source of the reserve respiratory capacity that is regulated by metabolic sensors and promotes cell survival. Cell Death Dis 6(7): e1835. https://doi.org/10.1038/cddis.2015.202

26. Mbaya E, Oules B, Caspersen C et al (2010) Calcium signallingdependent mitochondrial dysfunction and bioenergetics regulation in respiratory chain complex II deficiency. Cell Death Differ 17(12):1855-1866. https://doi.org/10.1038/cdd.2010.51

27. Rani V, Deep G, Singh RK, Palle K, Yadav UC (2016) Oxidative stress and metabolic disorders: pathogenesis and therapeutic strategies. Life Sci 148:183-193. https://doi.org/10.1016/j.lfs.2016.02. 002
28. Malhotra JD, Kaufman RJ (2007) Endoplasmic reticulum stress and oxidative stress: a vicious cycle or a double-edged sword? Antioxid Redox Signal 9(12):2277-2293. https://doi.org/10.1089/ars.2007. 1782

29. Morimoto RI, Kline MP, Bimston DN, Cotto JJ (1997) The heatshock response: regulation and function of heat-shock proteins and molecular chaperones. Essays Biochem 32:17-29

30. Sano R, Reed JC (2013) ER stress-induced cell death mechanisms. Biochim Biophys Acta 1833(12):3460-3470. https://doi.org/10. 1016/j.bbamcr.2013.06.028

31. Yadav D, Lowenfels AB (2006) Trends in the epidemiology of the first attack of acute pancreatitis: a systematic review. Pancreas 33(4):323-330. https://doi.org/10.1097/01.mpa.0000236733. 31617.52

32. Yadav D, Lowenfels AB (2013) The epidemiology of pancreatitis and pancreatic cancer. Gastroenterology 144(6):1252-1261. https:// doi.org/10.1053/j.gastro.2013.01.068

33. Danino H, Ben-Dror K, Birk R (2015) Exocrine pancreas ER stress is differentially induced by different fatty acids. Exp Cell Res 339(2):397-406. https://doi.org/10.1016/j.yexcr.2015.09.022

34. McCampbell A, Truong D, Broom DC et al (2005) Mutant SPTLC1 dominantly inhibits serine palmitoyltransferase activity in vivo and confers an age-dependent neuropathy. Hum Mol Genet 14(22):3507-3521. https://doi.org/10.1093/hmg/ddi380

35. Dawkins JL, Hulme DJ, Brahmbhatt SB, Auer-Grumbach M, Nicholson GA (2001) Mutations in SPTLC1, encoding serine palmitoyltransferase, long chain base subunit-1, cause hereditary sensory neuropathy type I. Nat Genet 27(3):309-312. https://doi. org/10.1038/85879

36. Bae YS, Oh H, Rhee SG, Yoo YD (2011) Regulation of reactive oxygen species generation in cell signaling. Mol Cells 32(6):491509. https://doi.org/10.1007/s10059-011-0276-3

37. Balaban RS, Nemoto S, Finkel T (2005) Mitochondria, oxidants, and aging. Cell 120(4):483-495. https://doi.org/10.1016/j.cell. 2005.02.001

38. Siskind LJ (2005) Mitochondrial ceramide and the induction of apoptosis. J Bioenerg Biomembr 37(3):143-153. https://doi.org/ 10.1007/s10863-005-6567-7

39. Zuellig RA, Hornemann T, Othman A et al (2014) Deoxysphingolipids, novel biomarkers for type 2 diabetes, are cytotoxic for insulin-producing cells. Diabetes 63(4):1326-1339. https://doi.org/10.2337/db13-1042

40. Guntert T, Hanggi P, Othman A et al (2016) 1-Deoxysphingolipidinduced neurotoxicity involves $\mathrm{N}$-methyl-d-aspartate receptor signaling. Neuropharmacology 110(Pt A):211-222. https://doi. org/10.1016/j.neuropharm.2016.03.033

41. Condrescu M, Reeves JP (2001) Inhibition of sodium-calcium exchange by ceramide and sphingosine. J Biol Chem 276(6): 4046-4054. https://doi.org/10.1074/jbc.M006862200

42. Sharma C, Smith T, Li S, Schroepfer GJ Jr, Needleman DH (2000) Inhibition of $\mathrm{Ca} 2+$ release channel (ryanodine receptor) activity by sphingolipid bases: mechanism of action. Chem Phys Lipids 104(1):1-11. https://doi.org/10.1016/S0009-3084(99)00106-1

43. Chik CL, Li B, Karpinski E, Ho AK (2004) Ceramide inhibits Ltype calcium channel currents in GH3 cells. Mol Cell Endocrinol 218(1-2):175-183. https://doi.org/10.1016/j.mce.2003.10.048

44. Park MK, Ashby MC, Erdemli G, Petersen OH, Tepikin AV (2001) Perinuclear, perigranular and sub-plasmalemmal mitochondria have distinct functions in the regulation of cellular calcium transport. EMBO J 20(8):1863-1874. https://doi.org/10.1093/emboj/20.8. 1863

45. Luo X, Shin DM, Wang X, Konieczny SF, Muallem S (2005) Aberrant localization of intracellular organelles, Ca2+ signaling, and exocytosis in Mist1 null mice. J Biol Chem 280(13):1266812675. https://doi.org/10.1074/jbc.M411973200 
46. Criddle DN (2016) Reactive oxygen species, $\mathrm{Ca}\left({ }^{2+}\right)$ stores and acute pancreatitis; a step closer to therapy? Cell Calcium 60(3): 180-189. https://doi.org/10.1016/j.ceca.2016.04.007

47. Shore ER, Awais M, Kershaw NM et al (2016) Small molecule inhibitors of cyclophilin D to protect mitochondrial function as a potential treatment for acute pancreatitis. J Med Chem 59(6):25962611. https://doi.org/10.1021/acs.jmedchem.5b01801

48. Auranen M, Toppila J, Suriyanarayanan S et al (2017) Clinical and metabolic consequences of L-serine supplementation in hereditary sensory and autonomic neuropathy type $1 \mathrm{C}$. Cold Spring Harb Mol Case Stud 3(6):a002212. https://doi.org/10.1101/mcs.a002212

49. Fridman V, Suriyanarayanan S, Novak P et al (2019) Randomized trial of l-serine in patients with hereditary sensory and autonomic neuropathy type 1. Neurology 92(4):e359-e370. https://doi.org/10. 1212/WNL.0000000000006811

50. Dunlop RA, Cox PA, Banack SA, Rodgers KJ (2013) The nonprotein amino acid BMAA is misincorporated into human proteins in place of $\mathrm{L}$-serine causing protein misfolding and aggregation. PLoS One 8(9):e75376. https://doi.org/10.1371/journal.pone. 0075376

51. Levine TD, Miller RG, Bradley WG et al (2017) Phase I clinical trial of safety of L-serine for ALS patients. Amyotroph Lateral Scler Frontotemporal Degener 18(1-2):107-111. https://doi.org/10.1080/ 21678421.2016.1221971

52. Soto D, Olivella M, Grau C et al (2019) 1-Serine dietary supplementation is associated with clinical improvement of loss-of-function GRIN2B-related pediatric encephalopathy. Sci Signal 12(586): eaaw0936. https://doi.org/10.1126/scisignal.aaw0936

53. de Koning TJ (2006) Treatment with amino acids in serine deficiency disorders. J Inherit Metab Dis 29(2-3):347-351. https://doi.org/ 10.1007/s10545-006-0269-0

54. Zhou X, He L, Zuo S et al (2018) Serine prevented high-fat dietinduced oxidative stress by activating AMPK and epigenetically modulating the expression of glutathione synthesis-related genes. Biochim Biophys Acta Mol basis Dis 1864(2):488-498. https://doi. org/10.1016/j.bbadis.2017.11.009

55. Zhou X, He L, Wu C, Zhang Y, Wu X, Yin Y (2017) Serine alleviates oxidative stress via supporting glutathione synthesis and methionine cycle in mice. Mol Nutr Food Res 61(11):1700262. https://doi.org/10.1002/mnfr.201700262

56. Zhang H, Hua R, Zhang B, Zhang X, Yang H, Zhou X (2018) Serine alleviates dextran sulfate sodium-induced colitis and regulates the gut microbiota in mice. Front Microbiol 9:3062. https:/ doi.org/10.3389/fmicb.2018.03062

57. Holm LJ, Haupt-Jorgensen M, Larsen J, Giacobini JD, Bilgin M, Buschard K (2018) L-serine supplementation lowers diabetes incidence and improves blood glucose homeostasis in NOD mice. PLoS One 13(3):e0194414. https://doi.org/10.1371/journal.pone. 0194414

58. Acton D, Miles GB (2017) Differential regulation of NMDA receptors by d-serine and glycine in mammalian spinal locomotor networks. J Neurophysiol 117(5):1877-1893. https://doi.org/10. 1152/jn.00810.2016

59. Dunlop RA, Powell JT, Metcalf JS, Guillemin GJ, Cox PA (2018) L-Serine-mediated neuroprotection includes the upregulation of the ER stress chaperone protein disulfide isomerase (PDI). Neurotox Res 33(1):113-122. https://doi.org/10.1007/s12640-017-9817-7

60. Gao X, Lee K, Reid MA et al (2018) Serine availability influences mitochondrial dynamics and function through lipid metabolism. Cell Rep 22(13):3507-3520. https://doi.org/10.1016/j.celrep.2018. 03.017

61. Othman A, Benghozi R, Alecu I et al (2015) Fenofibrate lowers atypical sphingolipids in plasma of dyslipidemic patients: a novel approach for treating diabetic neuropathy? J Clin Lipidol 9(4):568 575. https://doi.org/10.1016/j.jacl.2015.03.011

62. de Pretis N, Amodio A, Frulloni L (2018) Hypertriglyceridemic pancreatitis: epidemiology, pathophysiology and clinical management. United European Gastroenterol J 6(5):649-655. https://doi. org/10.1177/2050640618755002

63. Ewald N, Hardt PD, Kloer HU (2009) Severe hypertriglyceridemia and pancreatitis: presentation and management. Curr Opin Lipidol 20(6):497-504. https://doi.org/10.1097/MOL.0b013e3283319a1d

Publisher's note Springer Nature remains neutral with regard to jurisdictional claims in published maps and institutional affiliations. 